\title{
Disability and Deformity in Patients of Hansen's Disease Attending a Tertiary Care Centre in Nepal
}

\author{
Sagar Mani Jha, Nabin Bhakta Shakya, Sunil Shakya and Manisha Maharjan
}

Department of Dermatology and STI, Nepalese Army Institute of Health Sciences, Shree Birendra Hospital, Chhauni, Kathmandu, Nepal.

\begin{abstract}
Introduction: Leprosy is responsible for disability and deformity among patients. Nerve damage is one of the main features of leprosy and it is the main cause of disability in the patients. Developing deformity leads to restriction in professional work and hence reduced income as well as it also acts adversely on social wellbeing. The aim of this study was to study the spectrum of Grade 2 disability among all leprosy patients attending outpatient and inpatient according to WHO grading and to find the association with Ridley Jopling classification.

Methods: It was an observational cross sectional hospital based study. All the inpatients and outpatients of leprosy getting treatment and were on follow up in the Department of Dermatology between December 2017 to November 2019 were included. Details of disability and deformity were recorded and were Classified as per WHO grading and Ridley Jopling classification. Cross tab was used in descriptive analysis to compare between different variables and data was analysed in percentage.

Results: A total of 88 patients were included in the study. Maximum number of patients 41 (46.7\%) belonged to 30 to 50 years of age group. Various degrees of loss of sensation was seen in all patients and total number of patients with Grade 1 disability were 68 (77.3\%) and Grade 2 disability were $20(22.7 \%)$. Maximum number of patients $11(12.5 \%)$ with Grade 2 disability was seen in Lepromatous Leprosy.

Conclusions: Disability and deformity can occur in any spectrum of disease and intervention as early as possible will help reduce the incidence.

Key words: leprosy; nerves; spectrum
\end{abstract}

Correspondence: Sagar Mani Jha, Department of Dermatology and STI, Nepalese Army Institute of Health Sciences, Shree Birendra Hospital, Chhauni, Kathmandu, Nepal. E-mail:sagarmanijha@gmail.com.

DOI: http://dx.doi.org/10.3126/mjsbh.v19i1.26671

Submitted on: 2019-10-11

Accepted on: 2019-12-16

This work is licensed under creative common license:

http://creativecommons.org/licenses/by-nc-nd/4.0/ (C) MJSBH 2020 


\section{INTRODUCTION}

Leprosy is responsible for disability and deformity among patients. Nerve damage is one of the main features of Leprosy and it is the main cause of disability in the patients. ${ }^{1}$ Even in those patients who started treatment in time it was seen that patients developed disability and deformity. Early diagnosis and treatment leads to reduction of the number of disability significantly. In various studies it was shown that maximum number of patients belonged between 30 to 40 years of age. The prevalence of leprosy is gradually decreasing in many countries; however rates of new case remain at almost the same level globally and in different regions. ${ }^{2}$ They remain reminders of disease leading to social discrimination, economical constraints and loss of confidence among patients. ${ }^{3}$ Timely diagnosis of grade- 1 disability is required for disability limitation and mitigation. ${ }^{4}$ Developing deformity leads to restriction in professional work which reduces income as well and acts adversely on social well being. This study was done to find out types of deformity and disability in various age groups. This study was done to find out types of deformity and disability in various age groups of Leprosy patients. The study is aimed to help formulating a guideline in the Department for initiating early measures to prevent disability and deformity. It will also serve the dual purpose of educating the students as well as educating the patients and their relative to prevent themselves from disability and deformity. Very few studies on this topic have been done in our country and this study will give new dimension in prevention of deformity and disability. The aim was to study the spectrum of Grade 2 disability among all leprosy patients attending outpatient and inpatient in the Department according to WHO grading and to find the association between Ridley Jopling Classification with Deformity and Disability of Patients with Leprosy.

\section{METHODS}

It was an observational cross sectional hospital based study. All the inpatients and outpatients of leprosy getting treatment and those who were on follow up in the Department of Dermatology between December 2017 to November 2019 were included. Informed consent from patients participating in the study was taken. Patients and their relatives were described and explained the study methods. Clearance from Ethical Review Committee of Institution was taken. Details of disability and deformity were recorded and were classified as per WHO grading. ${ }^{5}$

WHO disability grading 1998 :

- Hands and feet

Grade 0: No anaesthesia, no visible deformity or damage.

Grade 1: Anaesthesia present but no visible deformity or damage.

Grade 2: Visible deformity or damage present.

- Eyes

Grade 0: No eye problem due to leprosy, no evidence of visual loss.

Grade 1: Eye problem due to leprosy present but vision not severely affected as a result of this. (vision 6/60 or better: can count fingers at 6 meters distance, corneal sensation testing - optional).

Grade 2: Severe visual impairment (vision worse than 6/60: Inability to count fingers at 6 meters distance), also includes lagophthalmos, iridocyclitis and corneal opacities.

Association of deformity and disability was analysed according to Ridley Jopling Classification (based on histology and immunity): TTTuberculoid leprosy, borderline tuberculoid (BT) leprosy, mid-borderline (BB) leprosy, borderline lepromatous, (BL) leprosy and polar lepromatous (LL) leprosy.

In this study a structured questionnaire was used to obtain history and information regarding leprosy, disability and deformity. These informations were recorded in the history sheet of the patients. All the data thus collected were used to analyse using cross tab in descriptive analysis to compare between different variables and data were expressed in 
percentage. The analysis was done using SPSS version 21 .

\section{RESULTS}

The total period of study was two years and a total of 88 patients were enrolled in the study. The cases included were newly diagnosed as well as old ones who were on regular follow up. Maximum number of patients $41(46.7 \%)$ belonged to 30 to 50 years of age group, males were $55(62.5 \%)$ and females were 33 (37.5\%). According to Ridley Jopling classification, the spectrum of disease is given in Table 1.

Out of all 88 patients maximum number of patients $30(34.1 \%)$ belonged to lepromatous leprosy and minimum belonged to borderline leprosy. Various degrees of loss of sensation was seen in all 88 patients and total number of patients with Grade 1 disability were 68 (77.3\%) and Grade 2 disability were $20(22.7 \%)$. Spectrum of deformity according to Ridley Jopling Classification is given in Table 2.

\section{DISCUSSION}

This study was conducted to study the spectrum of Grade 1 and Grade 2 disability among all leprosy patients according to WHO grading and Ridley Jopling Classification of Leprosy. The study included all the cases of leprosy for a duration of two years, including new and old cases, on treatment and not on treatment but on regular follow up. In this study it was found that 68 $(77.3 \%)$ patients had grade 1 disability and 20
Table 1. Distribution of patients according to Ridley Jopling classification $(\mathrm{n}=88)$

\begin{tabular}{|l|r|r|}
\hline $\begin{array}{l}\text { Ridley Jopling } \\
\text { Spectrum }\end{array}$ & Number & Percentage (\%) \\
\hline TT & 11 & 12.5 \\
\hline BT & 19 & 21.6 \\
\hline BB & 6 & 6.8 \\
\hline BL & 22 & 25 \\
\hline LL & 30 & 34.1 \\
\hline Total & 88 & 100 \\
\hline
\end{tabular}

(22.7\%) had grade 2 disability. WHO committee on leprosy estimated that the risk of impairment occurring in leprosy patient was $25 \%{ }^{6}$ Maximum number of patients $41(46.7 \%)$ belonged to 30 to 49 years of age group, further $16(18.2 \%)$ belonged to 20 to 29 age group making it total of $64.9 \%$. This is the main working group in Nepalese society and having leprosy in this age group adversely affects socio economic wellbeing of the people. Hands, feet and eyes are the most effected parts in disability and people of working age group depend on them for earning their livelihood. The occurrence of disability indicates some lacunae in leprosy control programme. ${ }^{4}$ In this study feet of the patients were involved more than hands and in a study conducted by Richardus, Finlay and Croft showed similar findings. ${ }^{7}$

The sequence of most prevalent deformity in a study conducted in a tertiary care centre at Mangalore showed foot ulcer and claw hand to be

Table 2. Spectrum of deformity according to Ridley Jopling classification $(n=88)$

\begin{tabular}{|l|l|l|l|l|l|l|}
\hline \multicolumn{3}{|l}{ Grade 1 disability } & \multicolumn{5}{l|}{ Grade 2 disability ( Visible deformities) } \\
\hline $\begin{array}{l}\text { Ridley Jopling } \\
\text { Spectrum }\end{array}$ & $\begin{array}{l}\text { Loss of sensation } \\
\text { with skin lesions }\end{array}$ & Claw hand & Wrist drop & Foot ulcer & Foot drop & $\begin{array}{l}\text { Ocular } \\
\text { disability }\end{array}$ \\
\hline TT & $10(11.3 \%)$ & - & - & - & - & $1(1.1 \%)$ \\
\hline BT & $18(20.4 \%)$ & - & $1(1.1 \%)$ & - & - & - \\
\hline BB & $6(6.81 \%)$ & - & - & - & - & - \\
\hline BL & $15(17 \%)$ & $1(1.1 \%)$ & - & $6(6.81 \%)$ & - & - \\
\hline LL & $19(21.5 \%)$ & $4(4.5 \%)$ & $1(1.1 \%)$ & $5(5.6 \%)$ & $1(1.1 \%)$ & - \\
\hline Total & $68(77.2 \%)$ & $5(5.6 \%)$ & $2(2.2 \%)$ & $11(12.5 \%)$ & $1(1.1 \%)$ & $1(1.1 \%)$ \\
\hline
\end{tabular}


most common and in our study also similar results were seen. ${ }^{1}$ Among our patients with visible deformities, foot ulcer $(11,12.5 \%)$, was the most common followed by claw hand $(5,5.7 \%)$. As in a study conducted in West Bengal, deformity was seen more in feet $(12,13.6 \%) .{ }^{4}$ Maximum number of visible deformity was seen in $\operatorname{BL}(7,7.9 \%)$ and LL pole $(11,12.5 \%)$. Single patient had lagophthalmos in TT pole, he was taking treatment for tinea infection and came to the department only after he developed problem in eyes. In our study, males were $55(62.5 \%)$ and females were 33 $(37.5 \%)$ in contrast to a study in Nigeria where women were found to have more deformities than did men. ${ }^{8}$ Early detection and initiation of treatment as early as possible prevents disability and deformity. Hence timely intervention is required to reduce the case of grade disability. A study conducted in Bangladesh showed that early diagnosis and intervention can reduce disability by $30 \%{ }^{7}$

Single patient developed lagophthalmos because he was referred to dermatologist at a late stage when he had already developed disability. Early initiation of treatment with steroid is the main stay to prevent disability. Delayed treatment with steroids can lead to permanent nerve damage. ${ }^{9}$

Limitation of this study was relatively small sample size. Overall, the number of patients are decreasing and Ministry of Health and Population has declared elimination of Leprosy. Nevertheless the study is important because it gives a picture of disability and deformity among the patients of leprosy. The cases included in this study may not represent the situation of whole country but it definitely reflects the importance of detection and early intervention to prevent disabilities.

Global Strategy has aimed at 3 points, firstly to prevent completely grade 2 disability among children secondly to reduce the number of new leprosy cases with grade 2 deformity to less than 1 per million and thirdly all countries to have legislation against discrimination towards leprosy patients. ${ }^{10}$ Early detection, proper management and follow up of the patients as long as possible will help in reducing disability and hence morbidity. Patients education about the disease and disability care plays vital role in prevention of deformity. Further research is suggested including multiple centres receiving the patients with leprosy. This will give a more clear picture and about disability and deformity as this will include more number of patients in study. This will also help in formulating guidelines for a larger population for early intervention to prevent disability in the future.

\section{CONCLUSIONS}

Disability and deformity can occur in any spectrum of disease and intervention as early as possible can help reduce the incidence. Referring patients to leprologists and initiation of appropriate measures is of paramount importance. Timely treatment of reactions and patients education about the disease must be emphasised.

\section{ACKNOWLEDGEMENTS}

Faculties and Staff of Department of Dermatology and STI, NAIHS.

To cite this article: Jha SM, Shakya NB, Shakya S, Maharjan M. Disability and deformity in patients of Hansen's disease attending a tertiary care centre in Nepal. MJSBH. 2019;19(1):26-30.

Conflict of Interest: None declared

\section{REFERENCES}

1. Nayak AK, Satheesh R, Shashidhar K. Spectrum of physical deformities in leprosy patients visiting a tertiary care centre in Mangalore. Ann Trop Med Public Health. 2017;10:22-6.

DOI: https://doi.org/10.4103/1755-6783.205536

2. Tegta GR, Verma GK, Verma K, Negi AK, Gupta M. A clinico-epidemiological scenario of Leprosy at a tertiary care centre in sub-himalayan region: A seven year retrospective study. Indian J Lepr. 2019;91:7-16. 
3. Asia AJ, Tapre V, Asia AA. Epidemiological Profile of Disability in patients with Leprosy in a Tertiary Care Centre. Int J Sci Res. 2015;5(8):1-3.

4. Sarkar J, Dasgupta A, Dutt D. Disability among new leprosy patients, an issue of concern: An Institution based study in an endemic district for leprosy in the state of West Bengal, India. Indian J of Derm Ven \& Lepr. 2012; 78(3):328-334.

DOI: https://doi.org/10.4103/0378-6323.95449

5. WHO Expert Committee on Leprosy. Seventh Report. World Health Organisation. Tech Rep Ser. 1998; 874:1-43. Available from: https:/www.who.int > iris > handle

6. WHO Expert Committee on Leprosy. Second report Geneva: World Health Organisation. Tech Rep Ser. 1960; 459:1-31.

7. Richardus JH, Finlay KM, Croft RP, Smith WC. Nerve function impairment in leprosy at diagnosis and at completion of MDT:A retrospective cohort study of 786 patients in Bangladesh. Lepr Rev. 1996;67:297-305.

DOI: https://doi.org/10.5935/0305-7518.19960030

8. Peters ES, Elshiet AL. Male-female (sex) differences in leprosy patients in south eastern Nigeria: Females present late for diagnosis and treatment and have higher rates of deformity. Lepr Rev. 2002;73:262-7.

PMID: 12449892

9. Husain S. An attempt towards prevention and management of deformities and disabilities in leprosy. Indian J Lepr. 2011;83:9-14.

PMID: 21638978

10. World Health Organisation. Global Leprosy update 2015: time for action, accountability and inclusion. Weekly Epidemiological Record. 2016;91:405-20.

Available from: http://www.who.int/lep/resources/who_wer9135/en/. 